\title{
Whose Immigration Story?: Attending to Hidden Messages of Material in Social Studies
}

\author{
Eleni Oikonomidoy \\ Gwendolyn Williams \\ University of Nevada, Reno \\ U. S. A.
}

Sometimes materials used in schools with good intentions can have effects

opposite from those stated. Through the microscopic analysis of a parent-

student immigration interview assignment on a social studies unit on immigration, this article aims to uncover the hidden story that underlies the questions asked. In so doing, it intends not only to problematize the promotion of a simplistic and outdated narrative but also to use this analysis as a foundation for the development of a counter-narrative of complex and up-to-date attention to immigration. The article concludes with a developing checklist for evaluating existing and new material related to immigration.

\author{
Theoretical Foundation \\ Process \\ Analysis of Interview \\ Discussion \\ Implications for Practice \\ Notes \\ References
}

Curricular materials in schools have been critiqued for their emphasis on distant historical events and their neglect of controversial current topics (Gay, 2000). As such, they tend to operate out of certain ideological forces and create gaps and disconnects in students' understandings of historical events and in their development of critical social awareness. In the history of the United States, immigration has been and continues to be a central issue (Castles, 2003). Currently, the United States, like many other places in the world, is experiencing once again increasing waves of immigration from different parts of the world. Despite (or maybe because of) its long history of immigration, xenophobic sentiments still persist at the societal level (Critelli, 2008; Olneck, 2004).

Similar sentiments exist in schools. The impact of immigration in the social landscape of schooling has been explored (Hickey, 2005; Olsen, 1997; Rong \& Preissle, 1998; Suarez-Orozco \& Suarez- Orozco, 2001; Tran, 1998). Previous research suggested that demographic changes alter the social settings of schools, causing tensions to pre-existing configurations (Olsen, 1997; Valenzuela, 1999). Similarly, the educational attainment of immigrant students has been studied (Lee, 2001; Rong \& Preissle, 1998) enriching our 
understanding of this phenomenon. However, the theoretical frameworks that have been advanced in the social sciences in regards to the complex psychological, social, and academic aspects of immigrant students' integration in schools have not always been infused in immigrant-sensitive educational approaches (He, Phillion, Chan \& Xu, 2008), especially in parts of the country only recently impacted by newer immigration waves. For instance, Journell (2009) in his analysis of the standards of nine states found that the treatment of immigrant groups was inconsistent, outdated, simplistic, and oftentimes negative. This author argued that immigration in educational settings should not be primarily approached as a matter of demographics, but rather it should center on people's experiences, which can be elicited partially through personal stories. Similarly, others have proposed the importance of eliciting and intertwining the student's family histories into the discussion of immigration through studentfacilitated interviews (Chang, 2001; McBee, Bones, Mossop, \& Owens, 1998). This sounds like a promising approach; however, if not carefully facilitated, it could also be jeopardizing its efforts of inclusion of students. For instance, if the teachers who facilitate such a method are unaware of their own biases in relation to the subject matter (Rong, 1998) and incorporate biased questions, the effort to include is quickly transformed into exclusion. How can personal stories be elicited in ways that will allow for "respectful" recognition and valuing of all students' stories under the principles of multicultural education for inclusion (Banks, 2004; Bennett, 2007)? Such must be a matter of both process and content.

The purpose of this paper is to offer a critical analysis of a "student-parent" immigration interview assignment guide that is used in early elementary grades in a project on immigration. It thus aims to model a process of analysis, elements of which could be used to evaluate existing material or the development of new material related to immigration. Combining critical content analysis of the text with anecdotal information shared from parents who were asked to fill out the immigration interview assignment, the content-related goal is to bring to light the promotion of a uniform narrative of immigration in the United States. The vision of immigration as a long-ago, Western European journey is so pervasive that it overshadows the overtly stated purposes of the immigration interview assignment to "bring immigration to life." This uniform past-oriented and Eurocentric vision challenges the degree to which newcomer immigrant students from various parts of the world can identify with the material presented in school on a topic that has directly and indirectly impacted their lives. How can their stories be left out from a unit on immigration?

The development of a well-rounded historical and current understanding of national and global developments is central in the cultivation of responsible and active citizens (Parker, 2004). However, such an understanding cannot be facilitated with the promotion of one-dimensional or fragmented information. The outcome of the uneven and one-dimensional view of immigration can be a further alienation of both students and parents. To portray immigration as a unidirectional model of linguistic and cultural assimilation is becoming less 
representative of the present reality given that many students find themselves in a form of transnationalism (Taylor, 2008).

Although the immigration interview assignment is one symbolic micro-level instance of such alienation, within the overall climate of xenophobic curricular material and interactional intentions, it could strongly impact parents' and students' identification with school (Lindquiest \& Selwyn, 2000). After the analysis of the items on the assignment, the authors will offer some recommendations for inclusive, complex, and more current treatments of immigration in social studies, along with a developing checklist for practitioners who would like to critically analyze material that they may be using and/or developing.

\section{Theoretical Foundation}

Three interrelated assumptions provide the theoretical foundation of this paper. They all derive from the literature on immigration in the social sciences. Although they do not attend to a holistic view of the complex phenomenon of immigration, they do provide important insights for its sensitive treatment (or lack thereof) in social studies. The first attends to the chronological framework that seems to dominate the immigration narrative. The second identifies elements that contribute to the complexity of immigrants' lives in the host country. The third transcends the borders of the host country, attending to transnational ties.

The first assumption is the pervasive impact of immigration as a reality of the distant past, which takes place explicitly and implicitly in school approaches (Fuller \& Stone, 1998). Characteristically, Journell (2009) mentions that many times the discussion on immigration stops at Ellis Island. It seems that visions of Ellis Island are engrained in the historical memories of many U.S. citizens and are explicitly and implicitly promoted through the curricular and pedagogical approaches in schools. By itself this reality is not problematic, given that this was an important milestone in U.S. history. However, if such visions persist in the new millennium, they neglect to take into consideration the dynamic transformations of current migration journeys. It is true that migration is a highly political issue in the United States (Olneck, 2004), but one has to ask who is benefiting from the perpetuation of a static immigration narrative in light of the dynamic and multifaceted ones that exist in modern life in the United States and abroad.

Attending to immigration in static and simplistic ways (Journell, 2009) promotes binary oppositions that fail to take into account the complexity of the phenomenon. Many times the way that the narrative is discussed at the macrolevel is within a binary of challenges that immigration poses and contributions that immigrants make (Chang, 2001). It seems that such a macro-level division of the negative and the positive only from the perspective of the receiving society neglects the complexity by which current immigration shapes the lives of newcomers, as well as those who belong to older generations of immigrants in 
the United States. The pervasive character of "one-right-path" to the journey that ends at Ellis Island has to be problematized in light of the demographic characteristic of the new migration waves (Rong, 1998). This narrative promotes the discourse of the immigrant as "alien" and, coupled with the synergistic negative impact of popular culture and academic literature, intensifies the negative context of reception for immigrants (Valdivia, 2008). A dialectic relationship between the old and the new, the good and the bad, would seem more appropriate in grasping the complexity of current migration. Situating migration as a current phenomenon within its global context could counteract the simplistic views.

The second interconnected assumption is that the diversity of current migration will have to be examined taking into consideration the multiple variables that impact an immigrant's journey. These include status in the host country (refugee, immigrant, etc.), race, class, gender, and language. For instance, experiences of relocation vary widely, ranging from voluntary to involuntary migration, including refugees and Internally Displaced People (IDP) (Castles, 2003). Similarly, length of stay in the receiving country shapes the experiences of immigrants in multiple ways as they create their lives in a new culture (Miglietta \& Tartaglia, 2009). The theoretical construct of generation in immigration is of central importance here as is the exact number of years in the host country. The experiences of first-generation immigration are quite different from those who belong to $1.5^{1}$ or to second and subsequent generations (Lopez \& Stanton-Salazar, 2001; Olsen, 1997; Rumbaut \& Portes, 2001; Waters, 1999). For instance, the degree to which immigrants or children of immigrants identify with the home country is very different and depends on multiple factors such as length of stay in the home country, level of sustained interaction with family there, and travel. Similarly, socio-economic status factors shape the journeys of elite professionals very differently from those of under-skilled blue collar workers (Rong, 1998).

Suarez-Orozco and Suarez-Orozco (2001), advancing the concept of social mirrors, propose a typology of three identity models from which children of immigrants tend to operate. They are ethnic flight, adversarial, and transcultural. When children operate out of an ethnic flight model, they tend to distance themselves from their culture of origin and do not identify with that at all. In an adversarial style, they distance themselves from the school culture, disbelieving in its perceived impact in their lives. Finally, in the transcultural model, they tend to be successful in navigating the native and the host cultures. These identity models are negotiated within a given social context of school, according to the authors. For instance, a positive context would facilitate a transcultural identity while a negative one could promote an adversarial approach.

An indication of the characteristics of the context of reception can be found in the materials that are used for instruction, as well as the pedagogical interventions that facilitate learning. Moreover, if a newcomer student operates out of an ethnic flight model and tries to identify similarities with his/her classmates, primarily due to negative experiences in the past, as Olsen (1997), 
discusses, this student would try to hide his/her origin. If we as teachers promote a discourse of showcasing differences, we alienate the student who may struggle to disengage from what we perceive his/her home culture. Similarly, if we dig into the narrative of the family's history, we may be unwittingly evoking painful and shameful memories that family members may be trying to forget. In each case immigrants might not feel comfortable discussing their stories with their children. It is important to keep in mind the factors that differentiate immigrants' status in the host country and their experiences.

The third interrelated assumption is that current immigration should not be discussed solely within the geopolitical context of the host country (Camicia, 2007). The notion of "transnational" (Levvitt, 2001; Olmedo, 2004) will have to enter the discussion. Most likely some of our students, especially those with newcomer status, engage in ongoing and intense transnational activity in their lives, even if they are not always in control of the quantity and quality of their transnational ties (Orellana et al., 2001; Valdivia, 2008). They may be living in the native country for a part of the year, such as during vacations; they may be engaging in cultural exchange with their peers through the Internet. With the revolutionary skyrocketing of technological advances, transnational exchanges can easily occur through digital media. For first and 1.5 generation students who may be unable to visit their native country for multiple reasons (including distance or possible restrictions, such as the refugee status), the participation to the native community, real or imaginary (Anderson, 1996) could be facilitated through the media (Valdivia, 2008). This transnational element can have important implications in the treatment of immigration in the school material/interactions. If we want to create spaces within our classroom in which all our students find a sense of belonging, we cannot neglect the impact of transnational ties in their lives.

\section{Process}

This paper was inspired after a variation of the same immigration interview assignment that had been distributed in a public school for a project on immigration in the second grade reappeared in a slightly different form in a project on immigration in another school of the same school district in the fifth grade. The state where this school district lies has been experiencing new waves of immigration, which has led to a drastic increase of newcomer immigrant students in the local schools (although this is a relatively new phenomenon). The state standards tended to adopt a nation-bound approach to immigration, in that they highlighted the contributions of immigrants and the local and national responses to different waves of immigration. A nation-bound approach tends to focus on the contributions of immigration to the national interests of a particular society, while a global perspective portrays immigration as interaction of a human family (Camicia, 2007). 
The fact that one of the researchers was a newcomer immigrant sparked the initial interest. Consequently, informal conversations with newcomer immigrant parents took place with a focus on their reactions to the immigration interview assignment. Following the informal brainstorming with parents, a content analysis was conducted, using insights from critical discourse analysis (Fairclough, 1991). The analysis was guided by the assumptions discussed in the theoretical framework. Careful reading and re-reading of the material took place, along with a search for the identification of the source. Although it is not certain if this was the original source of the interview assignment, a site that included a version of it was located through an Internet search engine. The interview assignment was presented in a unit on migration in a lesson plan format entitled "Making Immigration Come Alive," and it was suggested for grades 4-8 (The American Immigration Law Foundation, 2009). It was found under a category entitled "Latest Lesson Plans" with a date of November 19, 2008. The proposed lesson had multiple activities that ranged from a focus and enactment of a journey to Ellis Island to finding information about the students' ancestors. Given that the focus of this paper is on the student/parent immigration interview assignment, this assignment will be treated as a unit by itself. The immigration interview assignment appeared in a local school district, slightly altered from the form presented on the website

The questions included in that altered form are analyzed here, using insights from the theoretical framework. The analysis focuses not mainly on what is left out of the question, but on who is left out. In order to make the analysis more vivid, a personal narrative is offered, impersonating two parents whose children are asked to fill out the immigration interview assignment with them and who try to understand what is being asked prior to filling it out. Two main questions guide the analysis: Who is represented in the material? Who is left out?

\section{Analysis of Interview Questions}

The analysis is centered on the questions that were distributed. Each question is analyzed separately, but an effort has been made to demonstrate that they are in a continuum. Therefore, the reactions follow an imaginary collective read-aloud ${ }^{2}$ of two parents as they read the questions. The dialogue is presented after each question, while key points are highlighted in the analysis that follows.

\section{Question 1: In what country were your ancestors born?}

- Hm... This question takes me back to Ancient times.

- Is this what the term ancestors implies? 
- I am not sure. Well, do we even have this information?

- I am not sure. Should we guess?

The use of the term "ancestors" in the immigration interview assignment is quite puzzling. First, it implies a long journey in one's family tree without specifying how long that has to be, leaving the question open to interpretation. For certain immigrant people who come from countries with long histories over many centuries, ancestors could go all the way to ancient times. They might ask themselves: How am I to interpret the term ancestors? How long back in time do I have to go? Given that I am in the United States when asked this question, I am wondering if the question is framed within the historical context of the birth of the United States. But is the proposed framework meant to start with the historical constitution of the United States in mind? So does one have to go back to the birth of the country? Second, it implies that all ancestors were born in one country. Such a premise is faulty, as many Americans have formed families across cultural backgrounds so that their heritage can be attributed to multiple cultures. Who would find this question easy to answer then?

In a first view, it seems that the narrative here would privilege EuropeanAmerican students, given that for some of them it would be easy to identify the country of origin of their ancestors. But is this true for all? For some EuropeanAmerican students, the information requested here could have been lost in the years that have passed since the ancestors' original migration. It seems that those who maintain family trees and closely monitor their families' genealogical tree would be privileged. One then wonders if this may be an issue of social class and status. Either way, there would be groups of students who would feel excluded from this question.

For those who were forced to migrate, like African Americans, historically this information may not be available. On the other hand, this question does not address people who were in the region before European settlement, such as Native Americans. For some reason this question seems to imply that there has to be another country in one's past...

\section{Question 2: Are there still family members in that country?}

- Oh! Okay. I see now. There has to be another country. It could not be this one!

- Are there still family members? What do you mean? They are all still there.

- Is there something wrong with this?

One more question with a past-framework in mind! The keyword "still" demonstrates this underlying reality. It almost operates out of the assumption that there must not be any family members remaining in the ancestral land. It would be the aberration of the norm, if indeed there are family members in "that" 
country. However, "that country" for newcomer immigrants may be what they consider "their" country. "That country" may be the place they call "home" and may be filled with memories of joy, nostalgia, family, friends, and happiness as they engage in transnational activities (or not). Now if we refer to it as that "distant" country, aren't we asking people to distance themselves from it?

In addition, the character of this question as a yes/no poses challenges to the reader, in that it prevents the immigrant's narrative from being told. This question also fails to address the impact that immigration has on the family, as immigration can reshape the social roles of individuals within the family (Clark, Glick \& Bures, 2009). Therefore, the question should not be if the family is still there, but how the family has changed as a result of immigration. However, to return to the original question, let's say that we find out family members are still living there. There is not a follow-up question that would promote connection to a transnational link. For instance, if so, who are they? When do you get to see them? Do they visit you? Do you visit them? Do you communicate with them? How? Here the digital media question could be quite appropriate. All these are missing, given that the question is going to be answered either with a negative or with an uncertainty. Either way there is no room for further elaboration of a potential positive response; the rich cultural context of the immigrant is lost.

\section{Question 3: Why did they leave the country of their birth?}

- Oh. Now I see it. They could not be there! They all had to leave. Hm...

- What comes to mind now that they had to leave?

- Potato famine, religious persecution, war, poverty, Ellis island...

- The past immigration story!

- Is there something wrong with my family members still being there and with me being here for other reasons?

How do we explain to young children why their family members did not leave and that there is no judgment for the choices that the family has made? As is often the case with newcomer immigrants, only one or two members relocate while the rest remain in the native country. Restrictions on immigration laws prevent reunification, many times. And if we wanted to view this from the children's perspective, we would wonder if our parents' responses do not conform to the prescribed expected answers, we may start thinking that there is something wrong with our families. Why did they not leave? Our teacher, who gave us this questionnaire, for sure wanted us to say that they did leave.

On the other hand, even if they did leave, do we really want to get an indepth explanation of the reasons why family members relocated? How is that going to facilitate understanding of the immigration story of the United States? It may be that for those whose "ancestors" migrated a long time ago this is not threatening information. The chronological distance in that case can really 
facilitate a distant view of the phenomenon. However, for recent migrants, this information can be quite uncomfortable and even threatening. For instance, the reasons for the relocation and the actual trips may not have been that pleasant. Do we want to enforce these discussions at home if the parents have not initiated them? What about illegal immigrants who are afraid to tell their story for fear of deportation? Such a question could be an unwelcome intrusion that revisits emotional wounds that have not completely healed (Lindquist \& Seldwin, 2000). This issue is challenging for first, 1.5, or second generation immigrants. Although the assumption that immigrants left to seek a better life in the prosperous United States may be true in some cases, such a rationale is a false assumption for other immigrants.

\section{Question 4: Who were the first members of your family to arrive here?}

- It was me!

- Yes, it was me and my brother.

- That was an easy answer. Good thing they did not ask for more here.

As students/parents now we are starting to get frustrated. We were among the first members and we arrived here a few years ago. Do the "first" members imply that there have to be more coming? What if this is not the case for us? It was just us. What if it is not possible for our family to follow? What if the other family members were not granted a visa to come? What if they were left behind in uncertain conditions? Once again, the question assumes a uniform story, one that is distant in time... What is the correct answer to this question? A name, an occupation, a generational number? Moreover, on its face, this question is sufficiently vague, so that it may not provide any meaningful data to enrich the student's understanding of immigration.

\section{Question 5: How did they get to the United States?}

- On a plane!

- How else could they get here?

- Hm... Is the assumption here that people came on a boat through Ellis Island?

- I feel bad we cannot share this narrative.

- Is there a correct response to this question?

- Well, this is another "easy" question to answer. I can't wait till this immigration interview assignment is over.

Here we are again! The question prompts the respondents to tell of their historical grand adventure of fleeing multiple European countries to escape 
famine or religious persecution and leaves us with the vision of a boat... How do people travel nowadays? It is interesting to note why this information is so important. It could be that the most important thing is that they are or we are here. Now, what if the first members who migrated here, including the students as well, walked to the United States... What if they were smuggled in as undocumented workers? Would we really want parents to disclose this information on the interview? How will it be used to facilitate understanding of immigration? It doesn't seem that this would be a symbol of pride, especially when shared among the other stories (the most prosperous ones that actually included a means of transportation). The only outcome of this could be associated with shame and embarrassment. Although this approach would promote the dramatic effects of the immigration narrative (that is the negative view of immigration and the stereotypes associated with it), it neglects to attend to the complexity of the journeys of immigration. Despite all the challenges, migration can be quite enriching for people. The exciting, life-changing decision has to be discussed before, during, and after the journey (Papastergiadis, 2000). Shouldn't that be a part of the questionnaire?

\section{Question 6: Are there any celebration or traditions that the family brought over that are still observed?}

- Well, we have many celebrations and traditions. The only problem is that nobody brought them over! We "left them behind" and we go on holidays there and observe them.

- Did we have to bring them over?

- Oh no! We messed up again!

Once again the keyword is "still"! In some cases, traditions are not "brought over" because certain people are highly active in their transnational cultural exchanges and go to their native country to celebrate the holidays. The geographic proximity allows them to do so. Or maybe it is their socio-economic status that allows them to travel frequently. So, the celebrations and traditions are left behind... But again, many people cannot recall any traditions from their distant past that is still being practiced. Why is this so important? Furthermore, the question reduces the concept of culture to superficial representations like "fun and fiestas" and minimizes the profound ways that culture influences people's lives. Oftentimes, elementary school activities ask students to draw pictures of ethnic foods or holidays from other cultures. However, such activities prevent students from seeing immigration as a continuing current event that contributes to a modern multicultural society. 


\section{Question 7: Can you share any interesting information about your family or their immigration to this country?}

- What do you mean here? What do I need to share?

- I have no idea!

- Well, first of all this information is private. What should we share?

- Once again. Why are you asking? What exact information do you have in mind?

- Could it be that they are envisioning people on the boats going to Ellis Island only to be asked to go back?

- Or could it be that they really want to know the hardship that my friend's family experienced during the immigration journey?

- Probably not. They would not want you to include any painful information. Most likely what they are referring to is a funny story showing a warm welcoming.

- And if these stories are not known? Are we left out again?

- No! I am just going to put "No" in the response.

- I am going to turn this in so my child can get the points for the assignment....

It is not clear what interesting information about one's family would look like. It has been the authors' experience that, as one becomes more familiar with the traditional immigration journey in the United States, one tends to think that this question would try to elicit either traumatic experiences that family members encountered during the journey to Ellis Island or some connections of one's genealogical tree to the past presidents of the United States. The first one may not be applicable to newcomer immigrants and the second one would only be applicable to European-Americans with a long historical presence in the country. Even in that case, what one finds as interesting or not is quite subjective and culture-specific. Although the open-ended character of the question is welcomed, it is puzzling to a parent to figure out what an answer should be. Given the frustrating journey of answering the previous questions, it is no surprise to hear that people just choose a simple "No" as an answer to this question. Maybe, this was not bad after all. One-word answers were easy for many questions... Was this the goal of this immigration interview assignment, though?

\section{Discussion}

The brief analysis of the immigration interview assignment demonstrates the persistence of the past-framed, Eurocentric narrative of immigration. With the perpetuation of uniform narratives of migration like this one, it is quite unlikely that newcomer immigrant students, among others, will be able to find a place of 
identification at school. What is especially problematic with this immigration interview assignment is that the implicit outcomes are contradictory to the actual agenda that it aims to promote - that is, to bring immigration to life. This way, it serves to leave behind the experiences of newcomers who may be first, 1.5, or second generation and may live very active transnational lives (Orellana, et al., 2001; Valdivia, 2008), real and imaginary through their own experiences and those of their families. The immigration interview assignment also leaves behind those who may have had negative experiences prior or during the migration journey and do not want to share, intruding in unwelcomed ways (Lindquist \& Selwyn, 2000). It also leaves behind those second-generation students who may be operating out of an ethnic flight identity model (Suarez-Orozco \& SuarezOrozco, 2001) and would do anything to divert attention away from their native country.

Leaving a large portion of immigrant students alienated from its content, it appears that the immigration interview assignment achieves the opposite of what it proposes. Instead of bringing immigration to life, it recalls fragmented, pastoriented notions of immigration that could not provide means for identification for diverse groups of students. Furthermore, the search for specific answers to the questions prevents the telling of stories that would bring immigration to life. For instance, there is no mention of languages in this instrument, yet many immigrants spoke (and speak) languages other than English when they arrived in America.

What is especially troublesome about this immigration interview assignment is that teachers who use it in their classrooms may feel that they are going out of their way to promote an inclusive narrative of immigration. With the lack of an awareness of one's biases (Rong, 1998) this becomes the most dangerous part of this attempt. By neglecting key factors in immigrant students' lives through outdated material, the idea of inclusion is promoted, burying the exclusion of students' own lived experiences with immigration. It could be that the teacher may find it easy to respond to the immigration interview assignment, but this is not the case for parents and students who come from very different places.

The larger question that begs to be answered is how the information gained from this immigration interview assignment will be used in the future. Will it be included to promote an assimilationist superficial narrative (Olsen, 1997) of "despite all the differences, we are all alike in the melting pot" or will it be used to facilitate critical analysis of and dialogue on the diversity of our experiences and their socially constructed character? It should be noted that the immigration interview assignment is just a microscopic element of a whole unit on immigration. The units exist within a larger socio-political context that tends to have negative views of immigration, at least for those making up the majority of the immigrant population with recent immigration status (Critelli, 2008; SuarezOrozco \& Suarez-Orozco, 2001). The question then becomes what can be done within education to counteract the negative forces and promote understanding and a sense of solidarity and cohesion. 


\section{Implications for Practice}

The implications of this analysis for practitioners are situated within two general areas, at the macro-level and the micro-level.

\section{Macro-level: Creating a Theoretical Framework}

Given the pervasive character of the dominant immigration narrative in and out of schools, it seems that the systematic infusion of a counter-narrative throughout the material and interactions is central. If teachers are to lead the way to the promotion of alternative narratives of immigration, then they will have to be(come) knowledgeable of current theoretical frameworks that attend to the phenomenon.

Furthermore, if the counter-framework is to be effective, it will have to be widespread, sustained, and longitudinal. This paper's analysis shows that the dimensions that will have to be examined should include a focus on current immigration, a global transnational scope (Olmedo, 2004), a multidimensional complex analysis, and a critical and dialectic view of the positives and negatives. Of course, this would be preceded by teachers' own preparation and counteraction of biases (Rong, 1998). The weight comes partially on multicultural education pre-service and in-service teacher education. Bicultural, binational, or multicultural identities are the norm in our days. Analysis of migration cannot overlook these realities. Issues of belonging will have to be approached with sensitivity throughout teacher education.

\section{Micro-level: Curricular and Pedagogical Practice}

It seems that in order for the theoretical framework to get widespread application in educational practice, the critical analysis, evaluation, elimination, and adaptation of outdated material is critical. The critical question of who is represented in the material related to immigration is central. Lindquist and Selwyn (2000) propose ways in which assignments can elicit inclusive, but nonintrusive, stories. Following the principles of multicultural education, curricular material will have to be analyzed, and potentially revised, in order not to leave any group of students out (Gay, 2000). Picture books can be used to facilitate inclusive approaches (Baghban, 2007; Lamme, et al., 2004). Similarly, authentic sources describing immigrants' experiences from different time periods could be used. Some questions that could facilitate analysis and adaptation of the material could include:

- How can I allow/promote a current view of the immigration?

- How can I represent potential differences in generations of immigrants (or those with various lengths of stay in the United States)? 
- How are transnational links included in my curriculum?

- Could my questions be considered intrusive?

- Will all students (including non-immigrant ones) feel represented?

- How are various and different narratives promoted within the curriculum?

If one feels that he/she does not possess the skills necessary to engage in such a critical analysis, a "piloting" of the questions with the help of a colleague or friend who may be of immigrant background seems like a good place to start. Similar questions should not be asked only of the material but throughout the actual lesson and/or unit. Otherwise the material alone will be ineffective. Guest speakers, invited and engaged in conversations, could complement the presentation of information with authentic insights. Leaders in immigrant ethnic communities could be utilized as guest speakers themselves or as guides for the location of appropriate guest speakers. On the same note, parents could become partners in their children's education (He, Phillion, Chan \& Xu, 2008) by bringing in their critical insights. The main goal should be a comparative critical analysis of the past in light of the present and future, away from the promotion of a "master story" of an immigrant journey, while keeping in mind the complexity of pathways.

\section{Notes}

1. The term generation 1.5 refers to those who were born abroad and migrated at a very young age, spending their shaping years in school in the receiving country.

2. A read-aloud is a verbalization of one's thinking process while responding to a task in hand. In this case, reading the interview assignment would be the task. The read-aloud is considered collective because it includes two imaginary characters.

\section{References}

Auerbach, B. (2006). Strangers in a strange land: Read-alouds give us insight into others' struggles. School Library Journal, 52(10), 18-26.

Baghban, M. (2007). Immigration in childhood: Using picture books to cope. The Social Studies, 98(2), 71-76.

Banks, J. A. (2004) Multicultural education: Historical development, dimensions, and practice. In J. A. Banks \& C. McGee Banks (Eds.), Handbook of research on multicultural education (pp.3-25). San Francisco: JosseyBass. 
Bennett, C. I. (2007). Comprehensive multicultural education: Theory and practice (6th ed.). Boston: Allyn and Bacon.

Camicia, S. P. (2007). Deliberating immigration policy: Locating instructional materials within global and multicultural perspectives. Theory and Research in Social Education, 35(1), 96-11.

Castles, S. (2003). Towards a sociology of forced migration and social transformation. Sociology, 37(1), 13-34.

Chang, M. (2001). Immigration: A social studies unit for sixth grade. In G. J. Posner \& A. N. Rudnitsky (Eds.), Course design: A guide to curriculum development for teachers (pp. 243-259). New York: Longman.

Clark, R. L., Glick, J. E., \& Bures, R. M. (2009). Immigrant families over the life course: Research needs and directions. Journal of Family Issues, 30, 852872.

Critelli, F. M. (2008).The impact of September 11th on immigrants in the United States. Journal of Immigrant and Refugee Studies, 6(2), 141-167.

Foster, S. J. (2006). Whose history?: Portrayal of immigrant groups in U.S. history textbooks 1800-present. In S. J. Foster \& K. A. Crawford (Eds.), What shall we tell the children?: International perspectives on school history textbooks (pp. 155-178). Greenwich, CT: Information Age Publishing.

Fuller, C. \& Stone, M. E. (1998). Teaching social studies to diverse learners. Social Studies, 89(4), 154-158.

Gay, G. (2000). Culturally responsive teaching: Theory, research, and practice. New York: Teachers College Press.

Gibson, M. A., Bejinez, L. F., Hidalgo, N., \& Rolon, C. (2004). Belonging and school participation: Lessons from a migrant student club. In M. A. Gibson, P. Gandara, \& Koyama, J. P. (Eds.), U.S. Mexican youth, peers, and school achievement. New York: Teachers College Press.

He, M. F., Phillion, J., Chan, E., \& Xu, S. (2008). Immigrant students' experience of curriculum. In F. M. Conelly, He, M. F., \& Phillion, J. (Eds.), The Sage handbook of curriculum and instruction (pp. 176-197). Thousand Oaks, CA: Sage.

Hickey, G. (2005). 'This is American get punished' Unpacking narratives of Southeast refugees in the U.S. Intercultural Education, 16(1), 25-40.

Journell, W. (2009). Setting out the unwelcome mat: A portrayal for immigration in state standards for American history. The Social Studies, 100(4), 160168.

Lamme, L. L., Fu, D., \& Lowery, R. M. (2004). Immigrants as portrayed in children's picture books. The Social Studies, 95(3), 123-129. 
Lee, S. L. (2001). More than model minorities or delinquents: A look at Hmong American high school students. Harvard Educational Review, 71(3), 505529.

Levitt, P. (2001). The transnational villagers. Berkeley: University of California Press.

Lindquist, T., \& Selwyn, D. (2000). Doug's unit: Immigration. In Social studies at the center: Integrating kids, content, and literacy (pp. 83-154). Portsmouth, $\mathrm{NH}$ : Heinemann.

Lopez, D. E., \& Stanton-Salazar, R. D. (2001). Mexican Americans: A second generation at risk. In R. G. Rumbaut \& A. Portes (Eds.), Ethnicities: Children of immigrants in America (pp. 57-90). Berkeley: University of California Press.

McBee, R., Bone, K. Mossop. G., \& Owens, C. (1998). Teaching immigration in elementary classrooms. Social Education, 62(7), 417-419.

Miglietta, A., \& Tartaglia, S. (2009). The influence of length of stay, linguistic competence and media exposure in immigrants' adaptation. CrossCultural Research, 43(1), 46-61.

Olmedo, I. M. (2004). Raising transnational issues in a multicultural curriculum project. Urban Education, 39(2), 241-265.

Olneck, M. R. (2004). Immigrants and education. In J. A. Banks \& C. A. McGee Banks (Eds.), Handbook of research on multicultural education (pp. 310327). San Francisco: Jossey-Bass.

Olsen, L. (1997). Made in America: Immigrant students in our public schools. New York: The New Press.

Orellana, M. F., Thorne, B., Chee, A., \& Lam, W. S. E. (2001). Transnational childhoods: The participation of children in processes of family migration. Social Problems, 48(4), 572-591.

Papastergiadis, N. (2000). The turbulence of migration: Globalization, deterritorialization and hybridity. Cambridge, MA: Polity Press.

Parker, W. (2004). Diversity, globalization and democratic education: Curriculum possibilities. In. J. A. Banks (Ed.), Diversity and citizenship education: Global perspectives (pp. 433-458). San Francisco: Jossey- Bass.

Portes, A., \& Rumbaut, R. G. (1996). Immigrant America: A portrait. Berkeley: University of California Press.

Rong, X. L. (1998). The new immigration: Challenges facing social studies professionals. Social Education, 62(7), 393-399.

Rong, X. L., \& Preissle, J. (1998). Educating immigrant children: What we need to know to meet the challenges. Thousand Oaks, CA: Corwin.

Suarez-Orosco, M., \& Suarez-Orosco, C. (2001). Children of immigration. Cambridge, MA: Harvard University Press. 
Taylor, L. K. (2008). Of mother tongues and other tongues: The stakes of linguistically inclusive pedagogy in minority contexts. The Canadian Modern Language Review, 65(1), 89-123.

The American Immigration Law Foundation (2009). Making immigration come alive. Retrieved September $17^{\text {th }}, 2009$ from http://www.ailf.org/teach/ lessonplans/m11 makingimmigrationcomealive.pdf

Tran, M. T. (1998). Behind the smiles: The true heart of Southeast Asian American children. In V. O. Pang \& L. L. Cheng (Eds.), Struggling to be heard: The unmet needs of Asian Pacific American children (pp. 45-60). Albany: State University of New York Press.

Valdivia, A. N. (2008). Popular culture and recognition: Narratives of youth and identity. In N. Dolby \& F. Rizvi (Eds.), Youth moves: Identities and education in global perspective (pp. 101-114). New York: Routledge.

Valenzuela, A. (1999). Substractive schooling: U.S.-Mexican youth and the politics of caring. Albany: State University of New York Press.

Waters, M. C. (1999). Black identities: West Indian immigrant dreams and American realities. New York: Russell Sage Foundation. 